http://jmscr.igmpublication.org/home/

ISSN (e)-2347-176x ISSN (p) 2455-0450

crossref DOI: https://dx.doi.org/10.18535/jmscr/v7i12.145

Journal Of Medical Science And Clinical Research

IGM Publication

An official Publication of IGM Publication

\title{
The Current Status of Treatment among Migraine Patients in Bangladesh
}

\section{Dr Mohammad Kamrul Hasan ${ }^{1 *}$, Prof. Ismail Khan ${ }^{2}$, Dr Tahreema Salam³, Dr Methila Sharmin ${ }^{4}$}

${ }^{1}$ Assistant Professor, Department of Pharmacology, Shaheed Tajuddin Ahmad Medical College, Gazipur, Bangladesh

${ }^{2}$ Professor of Pharmacology, Dhaka Medical College, Dhaka, Bangladesh

${ }^{3}$ Lecturer, Department of Pharmacology, Shaheed Tajuddin Ahmad Medical College, Gazipur, Bangladesh

${ }^{4}$ Lecturer, Department of Pharmacology, Shaheed Tajuddin Ahmad Medical College, Gazipur, Bangladesh

*Corresponding Author

\section{Dr Mohammad Kamrul Hasan}

\begin{abstract}
Objective: In this study our main goal is to evaluate the current status of treatment among migraine patients in Bangladesh.

Methods: This randomized single blind cross over clinical trial was conducted at Department of Pharmacology, Dhaka medical college, Dhaka from July 2015 to June 2016. During the study, adult 64 migraine sufferers (without aura) attending in the Out Patient Department of neurology (Headache clinic), Dhaka Medical College Hospital, Dhaka. All data were recorded systematically in data collection form. One half of the samples were randomly allocated for group A and the other half to group B. Group A: 32 patients will be allocated for the prophylaxis of propranolol. Group B: 32 patients will be allocated for the prophylaxis of flunarizine.

Results: During the study, most common presenting complaints of group A were nausea (81.25\%), bothered by light/noise (68.75\%), vomiting (56.25\%), sparkling, flushing or colored light (37.5), and numbness/ tingling (25\%) and in group B were nausea (87.5\%), vomiting (65.62\%), bothered by light/noise (56.25\%), and spakling, flushing or colored lights (43.75\%).group A were nausea (81.25\%), bothered by light/noise $(68.75 \%)$, vomiting (56.25\%), sparkling, flushing or colored light (37.5), and numbness/tingling (25\%) and in group B were nausea (87.5\%), vomiting (65.62\%), bothered by light/noise (56.25\%), and spakling, flushing or colored lights (43.75\%). Where prior to second phase of treatment, four weeks were given for wash out for previous medication. Then crossover of treatment was done, i.e group A was assigned flunarizine and group B was assigned propranolol. During baseline the mean HUI score in both the groups were almost the same (mean scores in group $A$ and group $B$ were $0.33 \pm 0.13$ and $0.35 \pm 0.11$ respectively

Conclusion: The present comparative study between propranolol and flunarizine showed that propranolol was more effective for the prophylaxis of migraine without aura. It can be concluded from the study that propranolol should be used as an agent for the prophylaxis of migraine.

Keywords: Flunarizine, migraine, propranolol.
\end{abstract}

\section{Introduction}

Migraine is a neurological disease of which the most common symptom is an intense headache and is a common disabling primary headache disorder. Migraine, the second most common cause of headache, and the most common 
headache-related and indeed neurologic, cause of disability in the world, afflicts approximately $15 \%$ of women and $6 \%$ of men over a 1 -year period. ${ }^{1}$ Migraine has two major subtypes. ${ }^{2}$ Migraine without aura is a clinical syndrome characterized by headache with specific features and associated symptoms. Migraine with aura is primarily characterized by the transient focal neurological symptoms that usually precede or sometimes accompany the headache. Some patients also experience a premonitory phase, occurring hours or days before the headache, and a headache resolution phase. Premonitory and resolution symptoms include hyperactivity, hypo activity, depression, cravings for particular foods, repetitive yawning, fatigue and neck stiffness and/or pain. ${ }^{2}$

Since migraine attacks are often frequent they require management with agents that reduce their number. Such agents, although often effective, are ill- understood. It has been suggested that they work through four main mechanisms. 5- HT antagonism, modulation of plasma protein extravasation, modulation of central aminergic control mechanisms and membrane stabilizing effects through actions at voltage- sensitive channels. ${ }^{16}$ The mechanism of action is unrelated to its antidepressant activity. Flunarizine is a calcium channel blocker, most widely prescribed drugs for adults and adolescent. Propranolol is also one of the most commonly prescribed drugs for migraine prophylaxis. Exactly how $\beta$-blockers decrease the frequency of migraine attacks is not certain. The mechanism of action of betablockers in migraine prophylaxis is unknown; hypothesis include inhibition of central betareceptors modulation of 5-HT receptor activity, and cross- regulation of serotonergic pathways. ${ }^{1}$

In this study our aim is to evaluate the current status of treatment among migraine patients in Bangladesh.
Objective

\section{General Objective}

- To evaluate the current status of treatment among migraine patients in Bangladesh.

\section{Specific Objective}

- To detect symptoms other than headache

- To identify side effects among patients after treatment.

\section{Methodology}

\begin{tabular}{|l|l|}
\hline Type of study & $\begin{array}{l}\text { randomized single blind cross } \\
\text { over clinical trial. }\end{array}$ \\
\hline Place of study & $\begin{array}{l}\text { Department of Pharmacology, } \\
\text { Dhaka medical college, Dhaka. }\end{array}$ \\
\hline Study period & July 2015 to June 2016. \\
\hline $\begin{array}{l}\text { Study } \\
\text { population }\end{array}$ & $\begin{array}{l}\text { Adult } 64 \text { migraine sufferers } \\
\text { (without aura) attending in the Out } \\
\text { Patient Department of neurology } \\
\text { (Headache clinic), Dhaka Medical } \\
\text { College Hospital, Dhaka.. }\end{array}$ \\
\hline $\begin{array}{l}\text { Sampling } \\
\text { technique }\end{array}$ & Purposive \\
\hline
\end{tabular}

\section{Method}

In this study, one half of the samples were randomly allocated for group A and the other half to group B. Group A: 32 patients will be allocated for the prophylaxis of propranolol. Group B: 32 patients will be allocated for the prophylaxis of flunarizine. Data was collect at the Out Patient Department of Neurology (headache clinic), Dhaka Medical College Hospital, Dhaka. The samples were interviewed with a questionnaire. Pain intensity was assessed with a pain scale. All patients gave their informed consent before entering the study and the protocol of this study was approved by Local Ethical Committee of Dhaka Medical College. Each patient had a complete physical and neurological examination before the study.Patient suffering from migraine without aura according to International Headache Society criteria were randomly assigned to treatment.

\section{Data Analysis}

All data were recorded systematically in data collection form. Quantitative data were express as 
mean and standard deviation and qualitative data as frequency distribution and percentage. Data were edited prior to computer entry and analysis. Simple frequencies were calculated and multivariate analysis was done using SPSS software to determine the relationship among the different variables.

\section{Result}

Table 1 shows the age distribution of the patients of both groups. In group A $46.87 \%$ respondents were within 14 to 24 years age group which was followed by $31.25 \%$ within 25 to 34 years. In group B, $43.75 \%$ patients were within 15 to 24 years age group followed by $37.50 \%$ within 25 to 34 years. Mean age of the group A and group B was 29.28 and 28.22 years respectively. No statistical significance difference was observed between groups in term of age $(p>0.05)$. The following table is given below in detail:

Table 1: Distribution of the respondent's age by group

\begin{tabular}{|c|c|c|c|}
\hline Age (in year) & $\begin{array}{c}\text { Group A } \\
(\mathrm{n}=32)\end{array}$ & $\begin{array}{c}\text { Group B } \\
(\mathrm{n}=32)\end{array}$ & $\mathrm{P}$ value* \\
\hline $15-24$ & $15(46.87)$ & $14(43.75)$ & \\
\hline $25-34$ & $10(31.25)$ & $12(37.50)$ & \\
\hline $35-44$ & $4(12.50)$ & $4(12.50)$ & \\
\hline $45-49$ & $3(9.37)$ & $2(6.25)$ & \\
\hline Total & $32(100)$ & $32(100)$ & \\
\hline Mean \pm SD & $29.28 \pm 10.20$ & $28.22 \pm 10.27$ & 0.459 \\
\hline
\end{tabular}

In figure-1 shows gender distribution of the patients where out of all patients of group A $37.50 \%$ were male and $62.50 \%$ were female (male: female $=1: 1.66$ ) and in group $\mathrm{B}$ were
$34.37 \%$ were male and $65.62 \%$ were female (male: female $=1$ : 1.90). The following figure is given below in detail:

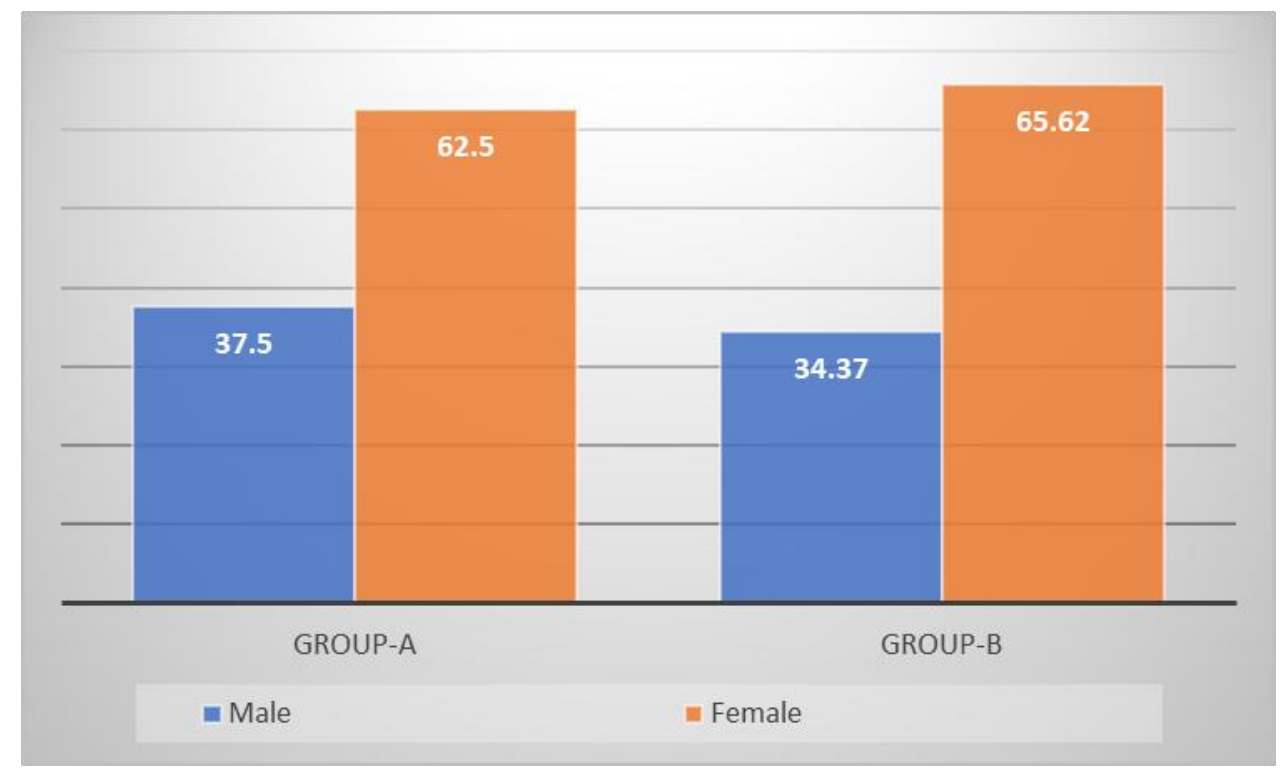

Figure-1: Gender distribution of the patients

In table- 2 shows distribution of the respondents by symptoms other than headache where most common presenting complaints of group A were nausea $(81.25 \%)$, bothered by light/noise 
(68.75\%), vomiting (56.25\%), sparkling, flushing or colored light (37.5), and numbness/tingling $(25 \%)$ and in group B were nausea (87.5\%), vomiting $(65.62 \%)$, bothered by light/noise $(56.25 \%)$, and spakling, flushing or colored lights
(43.75\%). No statistically significant differences were observed in term of presenting complaints in both the groups. The following table is given below in detail:

Table 2: Distribution of the respondents by symptoms other than headache

\begin{tabular}{|lccc|}
\hline Clinical complaints & $\begin{array}{c}\text { Group A } \\
(\mathbf{n}=32)\end{array}$ & $\begin{array}{c}\text { Group B } \\
(\mathbf{n}=32)\end{array}$ & P value* \\
\hline Nausea & $26(81.25)$ & $28(87.5)$ & 0.184 \\
Vomiting & $18(56.25)$ & $21(65.62)$ & 0.197 \\
Diarrhoea & $2(6.25)$ & $1(3.12)$ & 0.195 \\
Bothered by light/noise & $22(68.75)$ & $19(56.25)$ & 0.149 \\
Blurred/ double vision & $3(9.37)$ & $2(6.25)$ & 0.268 \\
Sparkling, flashing, or colored light & $12(37.5)$ & $14(43.75)$ & 0.476 \\
Feeling light headed & $1(3.12)$ & $1(3.12)$ & 1.00 \\
Numbness/tingling & $8(25)$ & $6(18.75)$ & 0.23 \\
\hline
\end{tabular}

In table-3 shows distribution of HUI score of both groups at $1^{\text {st }}$ phase of treatment where during baseline the mean HUI score in both groups were almost same, in group A it was $0.50 \pm 0.11$ and in group B it was $0.53 \pm 0.11$. After 8 weeks of prophylactic treatment the mean score reduced in both the groups, however, the reduction was more pronounced in group A. The difference of mean scores in both the groups (A and B) was statistically significant $(\mathrm{P}<0.0001)$. The following table is given below in detail:

Table 3: Distribution of HUI score of both groups at $1^{\text {st }}$ phase of treatment

\begin{tabular}{|lccc|}
\hline Group & $\begin{array}{c}\text { Baseline } \\
(\text { mean } \pm \text { SD })\end{array}$ & $\begin{array}{c}\text { At 8 weeks } \\
(\text { mean } \pm \text { SD })\end{array}$ & P value \\
\hline Group A (propranolol) & $0.50 \pm 0.11$ & $0.17 \pm 0.03$ & $<0.001$ \\
Group B ( Flunarizine) & $0.53 \pm 0.11$ & $0.21 \pm 0.04$ & $<0.001$ \\
\hline
\end{tabular}

In table-4 shows distribution of HUI score of both groups at $2^{\text {nd }}$ phase of treatment where prior to second phase of treatment, four weeks were given for wash out for previous medication. Then crossover of treatment was done, i.e group A was assigned flunarizine and group B was assigned propranolol. During baseline the mean HUI score in both the groups were almost the same (mean scores in froup A and group B were $0.33 \pm 0.13$ and $0.35 \pm 0.11$ respectively). The following table is given below in detail:

Table 4: Distribution of HUI score of both groups at $2^{\text {nd }}$ phase of treatment

\begin{tabular}{|lccc|}
\hline \multicolumn{1}{|c}{ Group } & $\begin{array}{c}\text { Baseline } \\
(\text { mean } \pm \text { SD })\end{array}$ & $\begin{array}{c}\text { At 8 weeks } \\
(\text { mean } \pm \text { SD })\end{array}$ & P value \\
\hline Group A (Flunarizine) & $0.33 \pm 0.13$ & $0.19 \pm 0.03$ & $<0.02$ \\
Group B ( propranolol) & $0.35 \pm 0.11$ & $0.16 \pm 0.03$ & $<0.001$ \\
\hline
\end{tabular}

In figure-2 shows distribution of patients of both treatment groups by side effects where in propranolol group the most side effects were, lethargy, orthostatic hypotension and difficulty in concentration. On other hand flunerizine group the most common side effect was dry mouth weight gain, palpitation and insomnia. The following figure is given below in detail: 


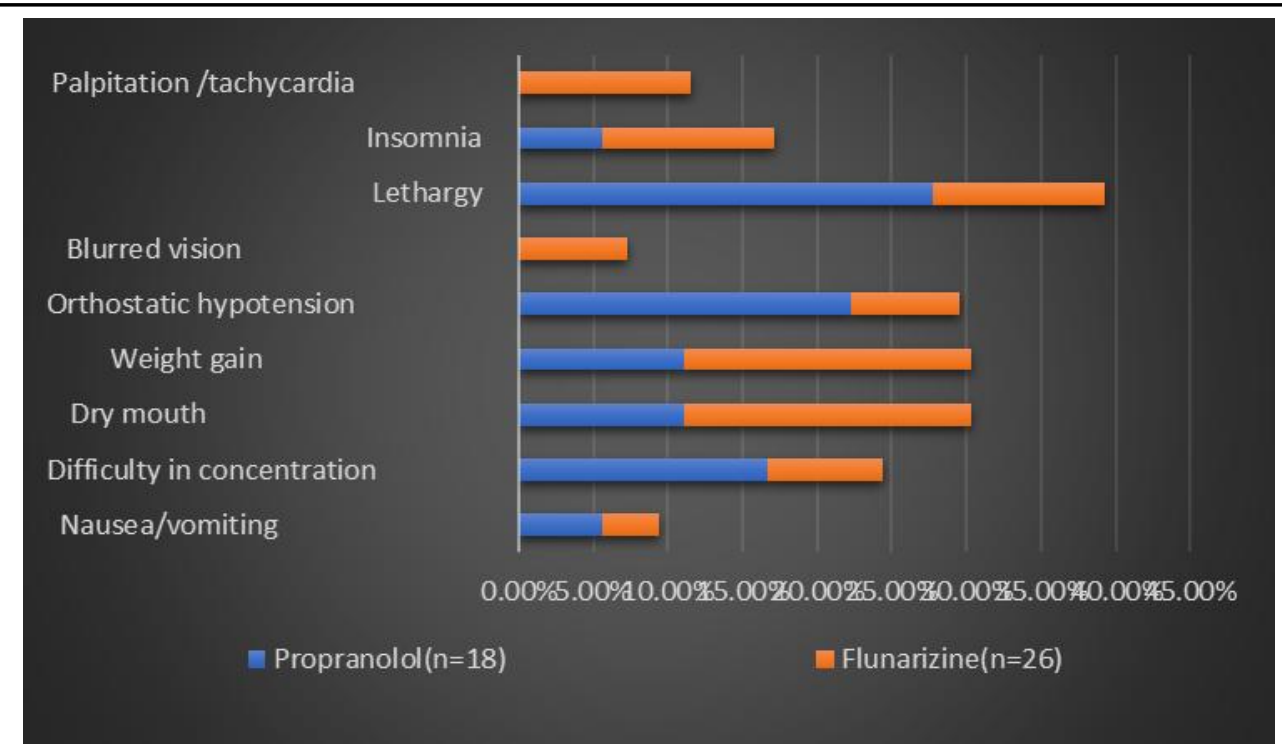

Figure-2: Distribution of patients of both treatment groups by side effects

\section{Discussion}

In this study the mean age of the respondents of group A and group B was $29.28(\mathrm{SD} \pm 10.2)$ and $28.22(\mathrm{SD} \pm 10.27)$ years respectively.

The most common presenting complaints other than headache among the respondents in the study include nausea $(81.25 \%)$, bothered by light/noise (68.75\% and vomiting $(56.25 \%)$. One study found that $7.1 \%$ of the migraine patients bothered by light. ${ }^{4}$ Another study reported that nausea was the most prominent feature of migraine. ${ }^{5}$

Maximum patients of both groups took acetoaminophen $(75 \%$ in group A \& $66.62 \%$ in group B), prochlorperazine $(68.75 \%$ in group A $\$ 71.87 \%$ in group B), diazepam $(56.25 \%$ in group A \& $62.5 \%$ in group B) as reliving remedial of their migranious pain. Regarding non-sterodial anti-inflammatory drugs, a randomized controlled trial found that naproxen can abort about one third of migraine attacks, which was $5 \%$ less than the benefit of sumatriptan. ${ }^{6}$ Paracetamol, at dose of $1000 \mathrm{mg}$, benefited over half of patients with mild or moderate migraines in a randomized controlled trial. $^{7}$

In the present trial the dose of Propranolol was 40 $\mathrm{mg}$ per day and Flunarizine was dosed as 10 $\mathrm{mg} /$ day. In another study showed that, doses of the drugs were maintained or raised comparing with the headache scores of the previous month. ${ }^{8}$ In another article reported that, total participant who completed the trial was sixty-two. ${ }^{9}$ The daily dosage was either 80 to $160 \mathrm{mg}$. propranolol, or an equivalent number of placebo capsules, for 4 to 8 weeks for the first medication and 8 weeks for the second one. At the end of the trial, 32 patients preferred propranolol and 18 patients preferred placebo. Those who preferred propranolol had greater reduction in severity and frequency of headaches and less consumption of analgesics and ergotamine than patients who preferred placebo. The effective dosage of flunarizine varies, but 5 mg orally each night should be given at first, followed by an increase of $5 \mathrm{mg}$ every week, up to $15 \mathrm{mg} / \mathrm{d}$.

In Propranolol group the side effects were 28.12\% and on the other hand in the flunarizine group the side effects were $40.62 \%$ in the present study. In Propranolol group the most common side effects were lethargy $(27.77 \%)$. Lethargy was also found as a common side effect in other study. ${ }^{2}$ On the other hand in the flunarizine group in this study the most common side effect was weight gain and dry mouth (19.23\%). This finding corroborates with the findings of another report. ${ }^{10}$

\section{Limitation}

- The study was single blind clinical trial. It would be more valid and reliable if it were double blind trial. 
- The present study was done in a single setting. The multi-centre study would be more representative of the population.

- The duration of the current study was only 8 weeks. To obtain more valid information it could be extended for a period of six months.

\section{Conclusion}

The present comparative study between propranolol and flunarizine showed that propranolol was more effective for the prophylaxis of migraine without aura. It can be concluded from the study that propranolol should be used as an agent for the prophylaxis of migraine.

\section{References}

1. Silberstein SD. Preventive migraine treatment. Neurol Clin. 2009 ;27(2):42943. PMID: 19289224.

2. Lainez MJ, Freitag FG, Pfeil J, et al. Time course of adverse events most commonly associated with topiramate for migraine prevention. Eur J Neurol. 2007;14(8):9006. PMID: 17662012.

3. Luykx J, Mason M, Ferrari MD, et al. Are migraineurs at increased risk of adverse drug responses? A meta-analytic comparison of topiramate-related adverse drug reactions in epilepsy and migraine. Clin Pharmacol Ther. 2009;85(3):283-8. PMID: 18987621.

4. Lipton RB, Bigal ME, Diamond M, et al. Migraine prevalence, disease burden, and the need for preventive therapy. Neurology. 2007;68(5):343-9. PMID: 17261680.

5. Olesen J, Bousser MG, Diener HC, et al. New appendix criteria open for a broader concept of chronic migraine. Cephalalgia. 2006;26(6):742-6. PMID: 16686915.

6. U.S. Food and Drug Administration. FDA News Release: FDA Approves Botox to Treat Chronic Migraine. 2010; www.fda.gov/ NewsEvents/Newsroom/ Press

7. Pascual J, El Berdei Y, Gomez-Sanchez JC. How many migraine patients need prolonged ( $>1$ year) preventive treatment? Experience with topiramate. $J$ Headache Pain. 2007;8(2):90-3. PMID: 17221343.

8. Goadsby PJ. How do the currently used prophylactic agents work in migraine? Cephalgia. 1997;17(2):85-92

9. Solomon GD, Santanello N. Impact of migraine and migraine therapy on productivity and quality of life. Neurology. 2000;55(9 Suppl 2):29-35. PMID: 11089517.

10. Hernandez-Latorre MA, Roig M. Natural history of migraine in childhood. Cephalalgia. 2000;20(6):573-9. PMID: 11075841. 